\title{
FIRE-STICK FARMING
}

\author{
by Rhys Jones
}

\section{Research Fellow, Department of Prehistory, Australian National University, Canberra, A.C.T.}

In recent years there has been increasing interest in the effect of man on the Australian environment. Forests have been bulldozed, swamps drained, heaths sown with trace elements, beaches chewed up, and the litter of the mid-twentieth century spread everywhere. That this is deeply affecting the countryside is obvious to all and causes concern to some. G.P. Marsh saw the same thing happening to the face of America during the last century, and doubtless the Roman intelligentsia of the rich provinces of North Africa gave the matter some thought as the wheatfields around their villas turned slowly into desert.

In most discussions a contrast is made between a "natural" environment as opposed to an "artificial" one. We imply that the former represents the climax without the effects of man, and as examples of it we think of bushland around our cities, the national parks, and remote areas. We imagine that the country seen by the first colonists before they ringbarked their first tree was "natural." But was it?

\section{Antiquity of Man in Australia}

The white man has been on this continent for 200 years in some places and less so in most others. Before he arrived, the continent had been colonized, exploited, and moulded by other men - the Australian Aborigines and their ancestors for tens of thousands of years [Figure 1].

Australian archaeology, in a decade's exciting research, has produced sequences of man's activities back into the Pleistocene in many places. The accompanying map [Figure 2] summarizes our present knowledge of man's antiquity in various parts of the continent; it can be seen that by 20000 to 30000 years ago

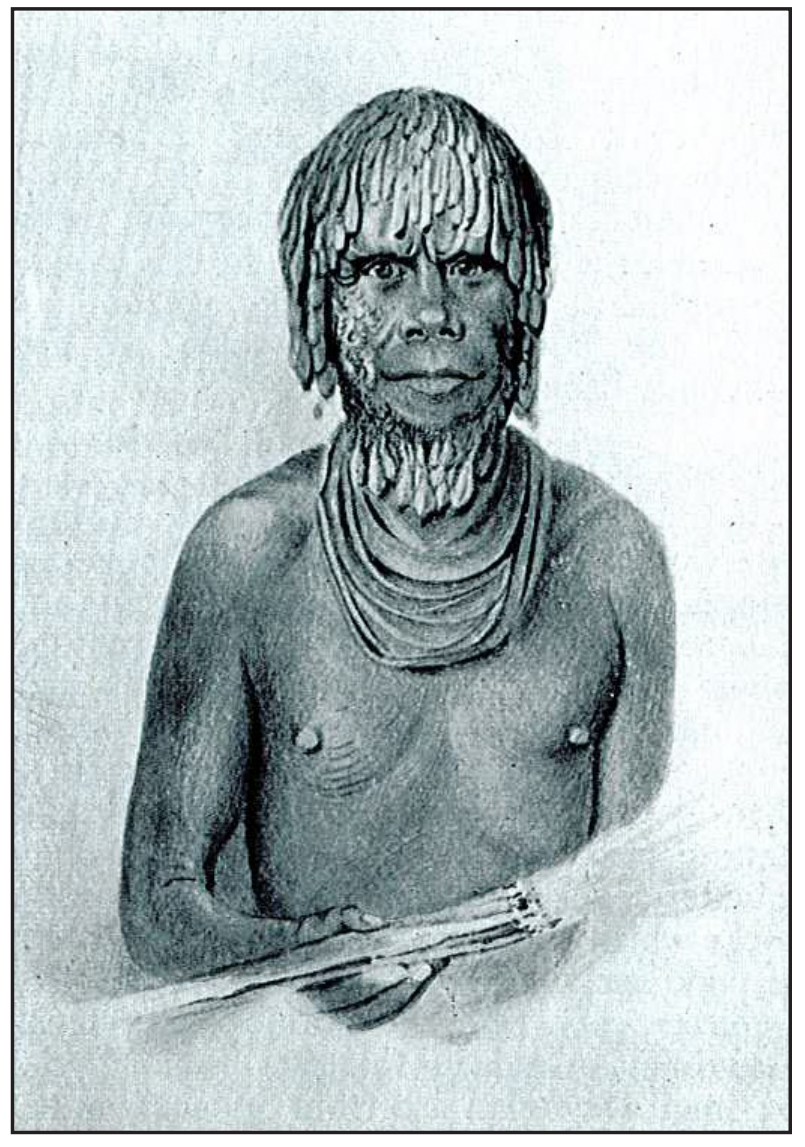

Figure 1. Mannalargenna, an Aborigine from the east coast of Tasmania, holding a burning fire-stick. (Watercolour painting by T. Bock, in the National Library, Canberra.)

he had colonized and extended his range throughout the inland plains of Australia and by 20000 years ago had reached the southeastern coast.

For a long time there has been a tendency to regard Aborigines, like most other hunters and gatherers the world over, as passive slaves of the environment, in contrast to the impact of agricultural or industrial man, who is seen as the master of nature, the initiator of ecological change. In recent years, however, the eco- 


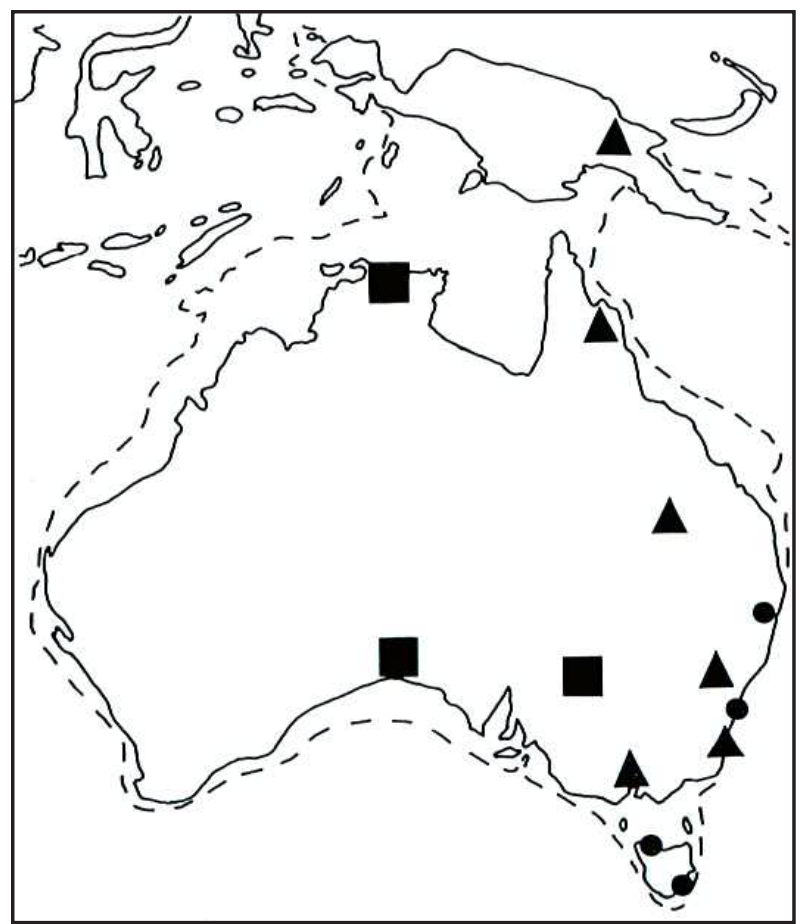

Figure 2. Summary of the present knowledge of man's antiquity in Australasia: squares indicate carbon dates between 21000 and 30000 years ago, triangles between 11000 and 20000 years ago, and circles between 5000 and 10000 years ago. The broken line represents the 100-fathom line which would have been the approximate coastline more than 10000 years ago. (Map by the author.)

logical effects of Aboriginal technology have been reinvestigated, and work by anthropologists on the living culture and by biologists on the environment suggests that these were enormous. They are still shaping our lives, even in areas where Aborigines have not roamed free for 100 years.

\section{Fire and the Aborigines}

Aboriginal man's ecological impact was mostly due to hunting, gathering of plants, and fire. By far the greatest effects were caused by the use of fire.

A study of Australian ethnographic literature will show that bushfires were systematically and universally lit by the Aborigines all over the continent. Explorers from Tasman onwards, seeing Australia from the sea, reported that the coastlines were dotted with fires. Peron, in 1802, sailing up Derwent in southeast Tasmania, said that "wherever we turned our eyes, we beheld the forests on fire." When men explored inland, the entire horizon was often filled with smoke from Aboriginal fires, and anthropologists have reported regular seasonal firings over hundreds of thousands of square miles in central and tropical Australia.

\section{Tasmania}

In Tasmania it was customary for the Aborigines to carry their smouldering fire-sticks with them, and they set fire to the bush they walked along. G.A. Robinson, who lived with them for the best part of 5 years, has hundreds of descriptions of their setting fire to the bush, of distant Aboriginal fires, and of large areas of countryside freshly burnt by them.

The ecological effects of these burnings have been studied by Tasmanian botanists, who can only account for the distribution of modern vegetation zones in Tasmania in terms of a long history of intensive Aboriginal fire pressure [Figure 3]. Many factors are involved in the distribution, such as soil type and aspect and climatic change, but a long history of firing has reduced the Notofagus-dominated rainforest in many places through a mixed eucalypt-rainforest phase to scrub and, eventually, to sedgeland and heath. W.D. Jackson sees the coastal sedgeland of western Tasmania as having been largely formed and extended as a result of constant firing, and as such it is a human artefact.

In eastern Tasmania, firing produced and maintained the open savannah woodland or parkland which greeted the first colonists, with their flocks of sheep. Here and there are extensive, open, treeless areas or "plains" covered with Poa grassland. These plains have been formed by repeated firing, and once there was a dense mat of grass on the surface it would have been kept clear not only by man 


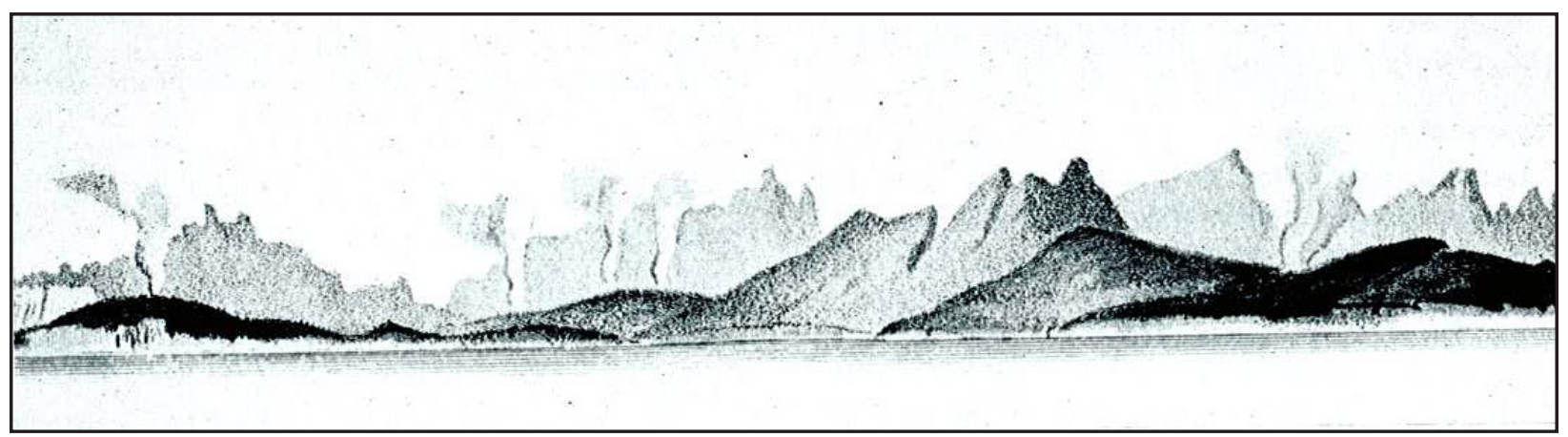

Figure 3. The east coast of Tasmania in 1802, showing smoke from Aborigines' bushfires. (Engraving after C.A. Lesueur, from the Nan Kivell Collection, National Library of Australia, Camberra.)

but also by the grazing of macropods, native hens, and other animals.

\section{Eastern New South Wales}

The savannah woodland, merging into open plains, characteristic of central and western New South Wales, is similar in many ways to that of eastern Tasmania and, again, has been heavily modified by Aboriginal burning. In 1848 Major Thomas Mitchell, the explorer, said with brilliant insight of these park woodlands:

Fire, grass, kangaroos, and human inhabitants seem all dependant on each other for existence in Australia... Fire is necessary to burn the grass and form those open forests, in which we find the large forest kangaroo; the native applies that fire to the grass at certain

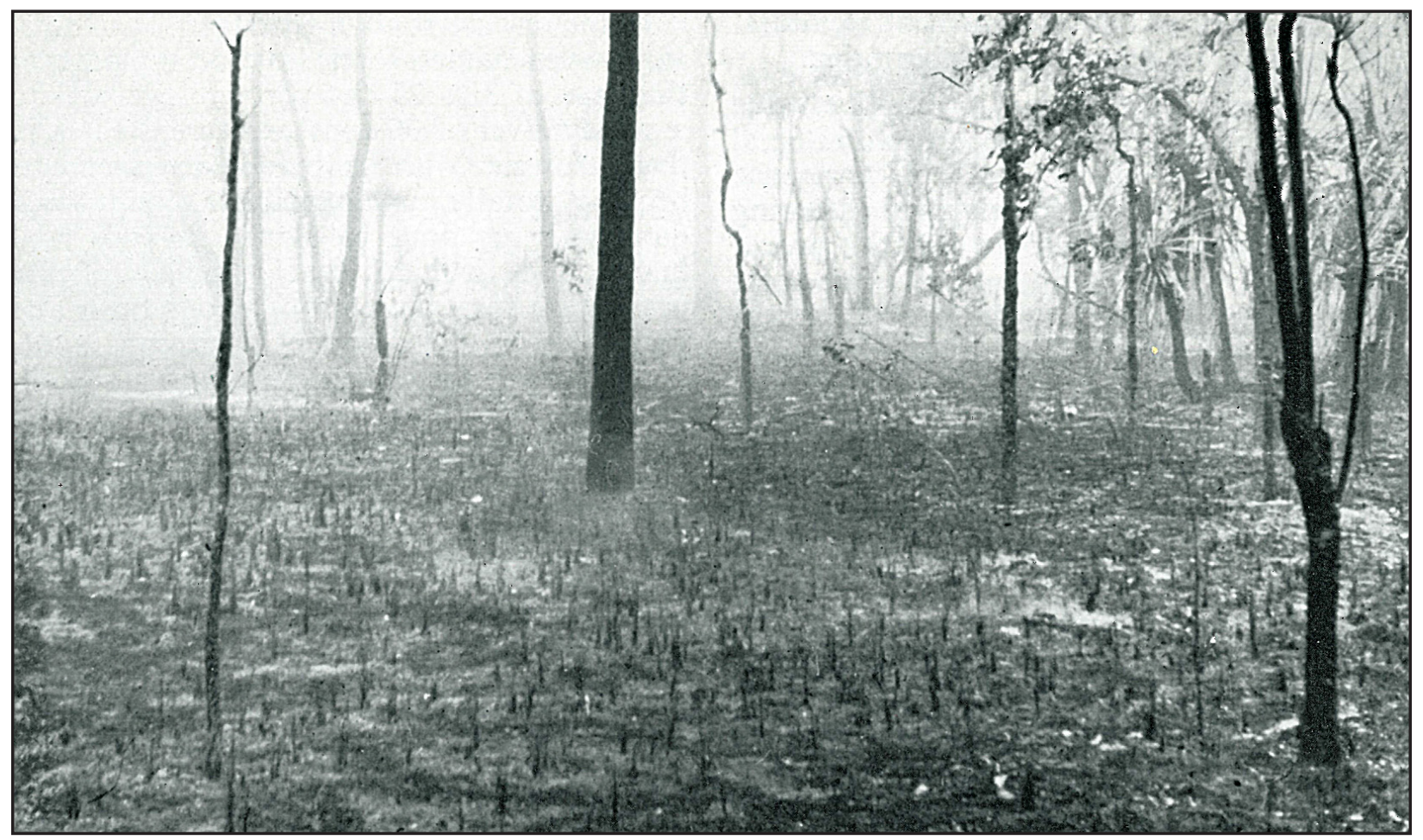

Figure 4. The bush immediately after an Aboriginal fire, northeastern Arnhem Land, 1967. Note the burnt grass, leaving a savannah, park-like distribution of trees. (Photo: Nicholas Peterson.) 
seasons, in order that a young green crop may subsequently spring up and so attract and enable him to kill or take the kangaroo with nets. In summer, the burning of the long grass also discloses vermin, birds' nests, etc., on which the females and the children who chiefly burn the grass, feed. But for this simple process, the Australian woods had probably contained as thick a jungle as those of New Zealand or America instead of open forests.

\section{Arnhem Land}

Arnhem Land, like other areas of tropical Australia, has a marked seasonal climate with a wet and a dry season. The Aborigines organized their life according to this pattern, and the firing of the bush during the dry season was a decisive part of their economy. In 1853, a visitor to the short-lived British settlement of Port Essington commented: "About the middle of the dry season, the natives set fire to the grass which is abundant everywhere, and at that time quite dry... The conflagration spreads until the whole country as far as the eye can reach, is in a grand and brilliant illumination." [Figure 4.] The Aborigines still do this, and the role of firing in their total economy has been extensively studied. The fires spread rapidly through the tall dry grass to the bases of the trees, and their ecological effects are maintenance of the open parkland appearance and inhibition of the spread and abundance of non fire-resistant plants.

N.B. Tindale accounts for the presence of patches of eucalypt and open plains in the Cape York rainforest as, again, being due to Aboriginal firing.

\section{Why Did Aborigines Burn the Bush?}

We can try to answer this question at several levels of sophistication:

- For fun: Anthropological friends of mine have asked Aborigines why they were tossing lighted matches into the bush from the back of land-rovers in which they were travelling. The answers have ranged from "it's fun" to "it's custom."

- Signalling: In the deserts, fires were used for signalling purposes either between bands or within them, so that the foraging people could know each other's whereabouts. In Tasmania, Aborigines tracked each other for peaceful or warlike purposes by fire spotting, and Robinson records women, abducted by sealers onto offshore islands, signalling to their kinsmen on the mainland by lighting great fires.

- To clear the ground: Both in western Tasmanian tea-tree scrub and in Arnhem Land grassland, the best way to clear a path is to set fire to the bush. This removes the undergrowth for easier travelling and also kills snakes and other vermin.

- Hunting: In many parts of Australia a recognized method of hunting was to set fire to the bush and club or spear the animals which broke cover. Foraging over the burnt area also revealed animals such as lizards hiding in holes or burnt to death on the ground.

- Regeneration of plant food: After firing, the Australian bush shows remarkable powers of regeneration. Eucalypts throw out new leaves, and grasses grow afresh from the burnt ground. Many of the vegetable foods eaten by the Aborigines are more palatable when young-for example, ferns, grasses, leaves and shoots of trees. By promoting the regrowth of grasses and young trees, man also provides a food supply for grazing and browsing animals. Aborigines will return to a burnt area after rain in order to hunt the game drawn there by the plants. This promotion of regrowth through firing is exactly the same process as that practised by modern farmers burning off the stubble in a wheatfield, or by Welsh hill shepherds burning off the mountainside each winter 
to kill the old bracken. In all cases, whatever the long-term effects may be, the immediate result of burning is to increase the quantity of edible plants for man and his beasts.

- Extending man's habitat: It is a thesis of mine that, through firing over thousands of years, Aboriginal man has managed to extend his natural habitat zone. In Tasmania, the climax vegetation along the western coast would be rainforest, which, according the distribution studies of the Aborigines, was not readily usable by them and was seldom penetrated. By burning, however, aided possibly by post-glacial climatic oscillations, man was able to push back the forest and replace it by sedgeland which is rich in both animal and plant food. In eastern Tasmania, human firing increased the extent of the mosaic pattern of open sclerophyll forest and grassland plains. This is optimum habitat for some macropods, such as the Forester Kangaroo, and the plains provided extra food for the kangaroos, wallabies, emus, and native hens on which the Aborigines fed. Mitchell, in the passage quoted above, clearly understood the symbiotic nature of man, grassland, and kangaroos.

\section{Increased Food Supply}

It is interesting that, through firing, man may have increased his food supply and thus probably his population. At the most general level, firing of the bush, in the same way as clearing a forest to create a field, increased the proportion of solar energy per unit area of the ground that man could utilize.

Perhaps we should call what the Aborigines did "fire-stick farming."

Was this deliberate? In some cases, yes; in others, no. Robinson records that a park-like landscape in Tasmania had been formed so as to give cover to the kangaroos. "This has been done by the natives: when burning the under- wood, they have beat out the fire in order to form clumps," he writes. R. Gould reports that Aborigines in the desert are quite clear that burning will attract kangaroos once rain has fallen.

On the other hand some of the effects take thousands of years to become recognizable, and no primitive people could possibly document these processes. However, it is in some ways as irrelevant to me whether or not the ancient Aborigines knew what they were doing as it is to paleontologists whether or not the giraffe knew why his neck was growing. If we are interested in the operations of laws of nature, we have to analyse the effects of certain actions or physical changes and see whether they are advantageous to the animal or culture involved. Taking a Darwinian line, according to the "principle of the survival of the fittest economy," to "explain" the acceptance and development of a cultural trait we have to show its adaptive value.

Firing, because of its great adaptive value to hunters and gatherers, became an integral part of the economy, and its presence throughout most of the hunting and gathering and agricultural economies of the world implies that it has a high antiquity and great importance in human evolution. Fire was man's first "extracorporeal muscle." Let us not forget that the power released by the disastrous Hobart bushfire on 7th February, 1967, was equivalent to two atom bombs.

\section{Results of the Removal of Aboriginal Fire Pressure}

Although fire has been an important factor in Australia for millions of years, natural fires being lit by lightning, etc., the arrival of $\mathrm{Ab}$ original man increased the fire frequency by an enormous amount. This produced and maintained disequilibriums, with the artificial extension of the range of pyrophytic plants. With the arrival of the Europeans, the Aborigines and their fire-sticks were promptly removed, 
and the effects of the cessation of regular burning were quickly noticed. Settlers in eastern Tasmania in the 1850 s commented that open sclerophyll forest became littered with bark and young shoots, with the grass becoming sour and weak. On the open plains of Surrey Hills in highland north Tasmania, the shepherds were increasingly frustrated by the growth of scrub, which, by 1890 , had obliterated most of the open land. The rainforest in Tasmania has spread from its gullies, and large areas of southwestern sedgeland have become covered with high, dense scrub.

In New South Wales, foresters have remarked that the maintenance of eucalypts on many high-quality sites depends on fire; otherwise, it would be replaced by other more tolerant genera. The resurgence of the cypress pine (Callitris) in western New South Wales may depend on the reduction of fire frequency. Some animals may have become adapted to a high fire regime and are more rare when this is reduced. It is interesting that Leadbeater's Possum, once thought to be almost extinct in Victoria, increased its numbers after several large fires had provided it with its preferred habitat.

In the dry sclerophyll forests of Tasmania, Jackson calculates, forest litter accumulates at the rate of 3 to $25 \mathrm{cwt}$ [Editor's note: Imperial $\mathrm{cwt}=112$ pounds] per acre per year to a steady level of 30 tons per acre. Fires in these forests with full fuel complements become totally uncontrollable, with vast damage being done to plants, animals, and man. It is ironical that a policy of fire prevention may have brought our bush and forests up to their present dangerous state, and the series of catastrophic fires in recent years may be the result of discontinuing the Aboriginal custom of regular burning. I have been interested in recent weeks to read that a policy of burning-off may be initiated as a new method of forest conservation.

\section{Fire and Conservation}

I am no botanist and would not venture a discussion on the long-term effects on plants and soil of firing or non-firing. However, as an anthropologist, I can state that at the time of ethnographic contact with the Aborigines, and probably for tens of' thousands of years before, fires were systematically lit by Aborigines and were an integral part of their economy.

What do we want to conserve? We have a choice. Do we want to conserve the environment as it was in 1788, or do we yearn for an environment without man, as it might have been 30000 or more years ago?

If the former, then we must do what the Aborigines did and burn at regular intervals under controlled conditions. The days of "firestick farming" may not yet be over.

\section{FURTHER READING}

Jackson, W.D., 1968 : "Fire and the Tasmanian flora," Tasmanian Year Book. 50-5. Hobart.

Jones, Rhys, 1968: “The geographical background to the arrival of man in Australia and Tasmania," Archaeology and Physical Anthropology in Oceania, 3, 186-215.

Merrilees, D., 1968: "Man the destroyer," Journal of the Royal Society of Western Australia, 51, 1-24.

Stewart, O.C., 1956: "Fire as the first force employed by man," in Man's role in changing the face of the earth, ed. W.L. Thomas. University of Chicago Press, Illinois, USA; 115-33.

Tindale, N.B., 1959: "Ecology of Primitive Aboriginal Man in Australia," in Biogeography and Ecology in Australia, ed. A. Keast, R.L. Crocker, and Christian. The Hague.

Reprinted from Australian Natural History 16(7): 224-228 (September 1969). 